Abstracta Iranica Abstracta Iranica

Revue bibliographique pour le domaine irano-aryen

Volume 24 | 2003

Comptes rendus des publications de 2001

Maisons d'Ispahan. Sous la direction de D. Diba, P. Revault et S. Santelli, Maisonneuve et Larose, Paris, 2001, 250 p. incluant 265 ill.

Monik Kervran

(2) OpenEdition

Journals

Édition électronique

URL : http://journals.openedition.org/abstractairanica/34454

DOI : 10.4000/abstractairanica.34454

ISSN : 1961-960X

Éditeur :

CNRS (UMR 7528 Mondes iraniens et indiens), Éditions de l'IFRI

Édition imprimée

Date de publication : 15 mai 2003

ISSN : 0240-8910

Référence électronique

Monik Kervran, «Maisons d'Ispahan. Sous la direction de D. Diba, P. Revault et S. Santelli, Maisonneuve et Larose, Paris, 2001, 250 p. incluant 265 ill. », Abstracta Iranica [En ligne], Volume 24 | 2003,

document 145, mis en ligne le 05 janvier 2010, consulté le 25 septembre 2020. URL : http://

journals.openedition.org/abstractairanica/34454; DOI : https://doi.org/10.4000/abstractairanica.

34454

Ce document a été généré automatiquement le 25 septembre 2020.

Tous droits réservés 


\title{
Maisons d'Ispahan. Sous la direction de D. Diba, P. Revault et S. Santelli, Maisonneuve et Larose, Paris, 2001, 250 p. incluant 265 ill.
}

\author{
Monik Kervran
}

1 Cet ouvrage, qui offre une très belle documentation photographique sur la ville et les maisons d'Isfahan, soutenue par un texte de qualité expliquant l'évolution de l'une et les caractéristiques des autres, résulte d'une coopération entre l'École des Beaux Arts de l'Université de Téhéran et l'École d'Architecture de Paris-Belleville/Université de Paris X-Nanterre.

2 Servie par une illustration peu abondante mais judicieuse, l'introduction évoque la formation de la ville d'Isfahan qui, comme toutes les villes qui ont réussi, a rendu impossible l'exploration de son passé. Vers 640 , au moment de la conquête arabe, elle se composait de deux quartiers principaux au nord du Zayandehroud, Jay et Jahoodiyeh. Son développement à l'époque islamique est classique et lorqu'elle devient la capitale des Seljukides au XI ${ }^{e}$ s., ayant absorbé les villages environnants, elle possède sa Grande mosquée à proximité du premier meydan (meydan-e-kohneh), son bazar, ses madrasa, ses caravanserails et ses bains.

3 Shah Abbas fait d'Isfahan sa capitale en 1590 et la structure par un grand axe nord-sud qui enjambe le Zayandehroud par le pont Allaverdi et rejoint, par le Chahar Bag puis les monuments de la ville safavide et le nouveau meydan, l'ensemble urbain de la vielle ville seljukide, au nord-est. Le Shah fait de cette oasis située au centre de l'aride plateau iranien, un paradis de verdure, auquel chaque maison de la ville contribue par sa courjardin.

4 Ce sont elles, les maisons d'Isfahan, qui sont le sujet de l'ouvrage. Les voyageurs européens des siècles derniers en ont décrit le charme, le confort ou le luxe cachés derrière d'austères façades, dans des ruelles dont l'insalubrité leur parut parfois rebutante. Le chapitre 4 livre le "sens et l'usage de la maison", structurée en une 
partie d'accueil, l'andarouni, et en résidence privée, le birouni, chacune munie d'une cour. Les maisons moins cossues n'en possèdent qu'une tandis que les plus riches peuvent en avoir une troisième, destinée aux services. Le sens symbolique des organes principaux de la maison est ici décrypté. Ouvrant sur le jardin, qui évoque le paradis, le talar ou pièce de réception, est remarquable par sa hauteur et son ornementation ; c'est le réceptacle des règles complexes de l'hospitalité. L'otagh, ou pièce à vivre, représente par sa disponibilité et sa flexibilité le caractère relatif et éphémère de la vie sur terre des habitants de la maison. L'entrée, ou hashti est basse, modeste, excentrée, donnant accès à chacune des parties du logis où le visiteur doit aller. Le seuil, enfin ou astaneh, formant généralement une dénivellation, marque «l'espace que l'on quitte pour celui où l'on va ".

5 Les deux chapitres suivants (5 et 6) portent un autre regard sur la maison d'Isfahan, le premier plus descriptif, le second plus structurel, avec d'inévitables redites de l'un à l'autre et avec le précédent. Puis vient le beau chapitre dont le titre résume le contenu : « la nature dans la maison »: il montre l'intégration de l'eau et de la verdure contenus dans le jardin à la vie de chaque partie de l'habitation. Viennent enfin l'étude des différents types de décors ornant la maison, puis celle des matériaux qui ont été mis en œuvre pour la construire.

INDEX

Thèmes : 5.1. Monde iranophone

\section{AUTEURS}

MONIK KERVRAN

CNRS - Paris 